
\title{
$\angle S$ Research Square \\ Is There a Clinical Significance of Very Low Serum Immunoglobulin E Level?
}

\section{Serdar Al ( $\nabla$ drserdaral@gmail.com )}

Dokuz Eylul University Faculty of Medicine: Dokuz Eylul Universitesi Tip Fakultesi https://orcid.org/0000-0002-4846-6761

\section{Suna Asilsoy}

Dokuz Eylul University Faculty of Medicine: Dokuz Eylul Universitesi Tip Fakultesi

\section{Nevin Uzuner}

Dokuz Eylul University Faculty of Medicine: Dokuz Eylul Universitesi Tip Fakultesi

\section{Gizem Atakul}

Dokuz Eylul University Faculty of Medicine: Dokuz Eylul Universitesi Tip Fakultesi

\section{Özge Atay}

Dokuz Eylul University Faculty of Medicine: Dokuz Eylul Universitesi Tip Fakultesi

Özge Kangallı

Dokuz Eylul University Faculty of Medicine: Dokuz Eylul Universitesi Tip Fakultesi

\section{Işık Odaman Al}

Pediatric Surgery Training and Research Hospital

\section{Özkan Karaman}

Dokuz Eylul University Faculty of Medicine: Dokuz Eylul Universitesi Tip Fakultesi

\section{Research Article}

Keywords: Adult, Autoimmune Diseases, Child, Immunoglobulin E, Primary Immunodeficiency, Neoplasms

Posted Date: April 29th, 2021

DOl: https://doi.org/10.21203/rs.3.rs-461902/v1

License: (c) (i) This work is licensed under a Creative Commons Attribution 4.0 International License.

Read Full License

Version of Record: A version of this preprint was published at Journal of Clinical Immunology on September 3rd, 2021. See the published version at https://doi.org/10.1007/s10875-021-01127-y. 


\section{Abstract}

Purpose: It has been well known that high serum immunoglobulin (Ig) E levels are associated with allergies, parasitic infections and some immune deficiencies; however, the potential effects and clinical implications of low lgE level on the human immune system are not well known. To determine the disorders accompanying very low IgE levels in children and adults.

Methods: The patients whose IgE levels were determined between January 2015 and September 2020 were analyzed, and the ones with an $\mathrm{IgE}$ level $<2.5 \mathrm{IU} / \mathrm{mL}$ were included in the study. Demographic data, immunoglobulin levels, auto-antibody results, and the diagnoses of the patients were noted from the electronic recording system of the hospital.

Result: The lgE levels were measured in 34,809 patients ( 21,875 children, 12,934 adults), and 180 patients had IgE levels $<2.5 \mathrm{IU} / \mathrm{mL}$. Eighty patients were children (0.37\%), 100 were adults $(0.77 \%)$. There was a malignant disease in 45 ( 11 of them children) (25\%), autoimmune diseases in 30 ( 4 of them children) $(16.7 \%)$ and immunodeficiency in 19 (16 of them children) (10.6\%) of the patients. The most common reasons were other disases, immunodeficiency and malignancy in children; and malignancy, autoimmune disorders and other diseases in the adults, in rank order. The lgE level did not show any correlation with the levels of other immunoglobulins.

Conclusion: Although rare, a low lgE level has been shown to accompany malignancies, autoimmune disorders and immune deficiencies. Patients with very low lgE levels should be carefully monitored for systemic disorders.

\section{Introduction}

The term IgE was first used in 1968, and IgE was shown to be an immunoglobulin involved in allergic conditions [1]. High IgE level is well known by clinicians, and is associated with allergies, parasitic infestations and, less frequently, various immune deficiencies. It has been known that a low lgE level is a warning for humoral immunodeficiencies, particularly when the levels of other immunoglobulins are also low [2]. Isolated immunoglobulin (Ig) E deficiency is defined as a significantly low IgE level [ $<2.5$ international units / milliliter $(\mathrm{IU} / \mathrm{mL})]$ in a patient with normal levels of other immunoglobulins, including IgG subclasses [3]. This is a laboratory finding that does not indicate a clinical disorder, and isolated IgE deficiency has not been included in international classifications for primary immunodeficiency disorders [4].

IgE deficiency ( $<2 \mathrm{IU} / \mathrm{ml}$ ) was determined in $3.3 \%$ of the US population. IgE deficiency has been observed in $75.6 \%(95 \% \mathrm{Cl}, 65.6 \%-85.7 \%)$ of the patients with common variable immunodeficiency (CVID), and has been suggested as an inexpensive screening test for this condition [5].

In animal studies, it has been shown that IgE plays a role in tumor immunity [6]. In human studies, an inverse relationship was found between atopy and various cancers (pancreas, brain, prostate, colorectal) 
[7]. The European Academy of Allergy and Clinical Immunology (EAACI) has reported an association between very low IgE levels and an increased risk for malignancy, and claimed that IgE level may be used as a new biomarker in diagnosis of cancer $[8,9]$.

The studies on low lgE levels and autoimmunity mostly emphasized IgE type of autoantibodies [10-12]. The pathogenesis of isolated low IgE levels has not been clarified. Defects in the immunoglobulin classswitch leading to the inability to produce IgE have not been clearly demonstrated [13]. However, activation-induced polymorphisms of cytidine deaminase gene in B lymphocytes have been blamed [14]. Although absence of IgE-producing B lymphocytes were shown in patients with IgE deficiency, its mechanism has not yet been clarified [15].

The relation of IgE deficiency with diseases is not clear enough. In some studies, this has been associated with other immunoglobulin deficiencies, autoimmune disorders, reactive airway disease (rhinosinusitis, bronchitis, asthma), susceptibility to sino-pulmonary infections, chronic fatigue and arthralgia $[3,8]$. The only study performed in children investigated its relationship with malignancy [16].

In our study, it was aimed to investigate the disorders associated with very low lgE levels, and the relationship of the IgE levels with the levels of other immunoglobulins in adults and children.

\section{Methods}

The patients who admitted Dokuz Eylul University Faculty of Medicine (DEU) Hospital between January 2015 and September 2020, and had an immunoglobulin E ( $\mathrm{lgE}$ ) level $<2.5 \mathrm{IU} / \mathrm{mL}$ were analyzed. The data were obtained retrospectively from the hospital medical recording center, and checked by two independent investigators. The patients' demographic data including age and gender as well as the levels of $\lg E$ and other immunoglobulins $(\mathrm{Ig}) \lg A$, $\operatorname{lgG}$, IgM, the presence of autoantibodies including anti-nuclear antibody(ANA), anti-double stranded DNA antibodies (anti dsDNA), extractable nuclear antigens (ENA panel), anti-thyroid peroxidase (Anti TPO), and anti-thyroglobulin (Anti TG) was recorded. The international disease classification (ICD-10) diagnoses of the patients were classified into groups including immunodeficiencies, malignancy, autoimmune disorders, atopic disorders, infections and the others, after examining the details of their archived files. Hematological and solid malignant tumors were included in the malignancy group. Vasculitis disorders including sarcoidosis, scleroderma, rheumatoid arthritis, systemic lupus, Hashimoto thyroiditis, type 1 diabetes mellitus, and autoimmune hemolytic anemia were included in the autoimmunity group. The patients diagnosed with asthma, allergic rhinitis, eczema, anaphylaxis, food allergy, and chronic urticaria were included in the group of atopic disorders. The disorders other than the aforementioned ones (neurological disorders, congenital heart disease, kidney diseases etc.) were included in the other diseases group. Low-normal-high levels of the immunoglobulins were determined in relation with the age of the patients, taking reference ranges into account for children and adults [17]. The values below -2SDS according to reference ranges were accepted as low immunoglobulin levels. The data were recorded on a standard registration form.

\section{Statistics}


The data were analyzed with IBM SPSS Statistics 22.0 (IBM Corp. Armonk, New York, USA) package program. The descriptive data were presented as the unit numbers $(n)$, percentage $(\%)$, and mean \pm standard deviation $(\bar{x} \pm s d)$, and the data that did not conform to normal distribution were given as median and minimum-maximum values. Inter-group comparisons were made with one-way analysis of variance for variables with normal distributions, and with Kruskal-Wallis analysis for variables without normal distributions. The multiple comparison tests used were Tukey HSD for normally distributed variables and Dunn-Bonferroni and Wellchs tests for non-normally distributed variables. Logistic regression test was used as a multivariate analysis to calculate probability ratios (ORs) and $95 \%$ confidence intervals $(95 \% \mathrm{Cl})$. Spearman correlation test was used to calculate the correlation among the immunoglobulin levels. Dependency of the categorical variables were analyzed using Chi-square, Yates correction and Fisher's exact tests. A p value $<0.05$ was considered as statistically significant.

\section{Results}

Between January 2015 and September 2020, 34,809 patients were identified who had their IgE levels measured; 21,875 of them were children ( $<18$ years of age), and 12,934 of them were adults ( $\geq 18$ years of age). In $180(0.52 \%)$ of these patients, the IgE level was $<2.5 \mathrm{IU} / \mathrm{mL} ; 80(44.4 \%)$ were children and 100 (55.6\%) were adults. The $\operatorname{lgG}$, IgA, IgM levels were analyzed after exclusion of extreme values of three cases diagnosed with multiple myeloma (Table 1). The disease groups with accompanying low IgE levels in children and adults are presented in Figure 1.

In the analysis of the adults and the children in relation with their diagnoses, it was seen that malignancy (34\%), autoimmune diseases $(26 \%)$ and other diseases $(15 \%)$ were the most frequent in adults, while other causes (37.5\%), immune deficiency (ID) (20\%)), and malignancy (13.75\%) were the most frequent disease groups in children.

The data of cases with malignancy are summarized in Table 2.

Autoimmune disorders were evident in $26(26 \%)$ adults and $4(5 \%)$ children. Autoantibodies were measured in 79 (43.9\%) patients, and 26 of them (3 children, 23 adults) were positive for autoantibodies. Autoimmune disorders and positive autoantibodies (p: 0.003 95\% Cl: 3.248-263.4) were correlated with female gender $(p<0.001 \chi 2=10.466, s d=1)$ and high IgG levels ( $p: 0.00895 \%$ Cl: 1.00-1.006). In four children diagnosed with autoimmune disorders, the diagnoses were SLE + lupus nephritis, psoriasis + spondyloarthropathy, IBD + epilepsy and autoinflammatory syndrome.

The characteristics of the adult patients are summarized in Table 3.

Immunodeficiency was detected in $16(20 \%)$ children and 3 (3\%) adults. CVID was observed in 2, and ataxia telangiectasia was seen in 1 adult patient. Ten (12.5\%) children had humoral ID, 3 (4\%) had severe combined immunodeficiency, and 3 had other IDs (ataxia telangiectasia, Di-George Syndrome, congenital neutropenia). A patient diagnosed with ataxia telangiectasia and non-Hodkgin lymphoma was included in the malignancy group. 
Atopic disorders were detected in 20 (11.1\%) patients, 7 of which were children. There was recurrent wheezing in 4, asthma in 2, atopic dermatitis in 1 of the pediatric cases. Among adults, asthma and/or chronic obstructive pulmonary disease was evident in 7, chronic urticaria in 4, and atopic dermatitis in 2 cases. Some of the cases with chronic urticaria (3 cases) had the diagnosis of Hashimoto thyroiditis, and were included in the autoimmunity group while the cases with idiopathic chronic urticaria (4 cases) were included in the atopic disorders group.

Various infections accompanied low IgE level in 11 (6.1\%) patients. Infective endocarditis, complicated pneumonia, meningitis, chronic otitis media, recurrent adenotonsillitis and pertussis were detected in 6 children, while bronchiectasis, tuberculous lymphadenitis, recurrent otitis, and skin infection (erysipelas) were detected in adults.

Neurological disorders were identified in $10(12.5 \%)$ of 30 children, who were classified in the other diseases group. Eight of them had resistant epilepsy, and were on multiple antiepilectics. Seven (8.75\%) had congenital heart disease (aortic arch anomalies), 4 (5\%) had genetic syndrome, 4 (5\%) had metabolic disorders, 2 (2.5\%) had chronic renal failure developed after focal segmental glomerulosclerosis and followed by kidney transplantation, and $3(3.75 \%)$ had severe protein energy malnutrition. Of 15 adult patients, 5 (5\%) had chronic renal failure (2 with kidney transplantation), 4 (4\%) diabetes mellitus, 4 (4\%) aplastic anemia, 1 Down syndrome and 1 notalgia paresthetica.

No pathologies were determined in 10 (5.6\%) cases, 6 of which were children.

IgE level was not correlated with the levels of other immunoglobulins. IgG and IgA levels were strongly correlated (rho: $0.636 \mathrm{p}:<001)$, while IgG and IgM (rho:0.529 p:<001) as well as IgA and IgM levels (rho:0.474 p:<001) were moderately correlated. These results indicate significant correlations among the levels of $\lg G$, IgA, and $\lg M$, however not with very low levels of $\lg \mathrm{E}$ (Figure 2).

Genders and the diagnosis groups were not correlated $(\chi 2=7.487, S D=6 p=0.278)$. When the diagnoses of all patients with low IgE levels were analyzed in relation with their ages, it was determined that the mean age of patients diagnosed with immunodeficiency was smaller $(p<0.05)$. (Figure 3 shows the age distribution of the patients in relation with the diagnoses)

\section{Discussion}

Recently, low IgE level has been a remarkable subject and a number of investigations have been carried on it. In our study, we aimed to identify the disease groups that might be associated with low IgE levels in children and adults. For this purpose, the patients whose IgE levels were determined in the last 5 years were screened. Among these, the patients with low lgE levels were analyzed for their diagnoses. Malignant and autoimmune disorders were detected in high rates. Low IgE levels did not show any correlation with the levels of other immunoglobulins. Autoimmune disorders were more frequent in patients who had autoantibodies, in females, and the ones with high IgG levels. The results of this study 
suggest that the role of $\operatorname{lgE}$ in the immune system, as well as its functions in malignancy and autoimmunity should be further clarified, and IgE deficiency should be taken seriously when encountered.

An IgE level $<2.5 \mathrm{IU} / \mathrm{mL}$ is defined as IgE deficiency. Its prevalence has been determined as $2.4 \%$ in the US population over the age of 6 years [18]. This prevalence was reported as $1.95 \%$ in a meta-analysis analyzing a number of cohorts [5]. The patients included in our study were those whose lgE levels were measured for any reason in our hospital. Therefore, our results do not present the prevalence in our society. In our study, an lgE level $<2.5 \mathrm{IU} / \mathrm{mL}$ was determined in $0.52 \%$ of the patients who had IgE level measurements.

The annual cancer diagnosis rate in Turkey is $0.28 \%$ [19]. The relationship between IgE level and cancer has been investigated in various studies. An inversely proportional relationship was shown between allergic sensitization and cancer development, high IgE levels were associated with a lower risk of multiple myeloma and Chronic Lymphoid Leukemia (CLL), and patients diagnosed with glioma and multiple myeloma had a longer life expectancy if their total IgE levels were high [20-25]. Studies that indicated high $\lg E$ and atopy might be protective against malignancy rationalised the opposite of this hypothesis, that is, the individuals with very low or undetectable IgE levels might have a higher malignancy prevalence and risk of developing tumors. When the patients with low lgE levels were compared with the ones with normal, high and very high IgE levels, a higher malignancy rate was found in the group with low IgE levels. It was reported that the group with IgE deficiency developed lymphoma (16\%) most frequently, and myeloma (8\%) was the second most common malignancy [26]. In a recent study, it was found that patients with $\mathrm{IgE}$ deficiency $(<2.5 \mathrm{IU} / \mathrm{ml}=\mathrm{KU} / \mathrm{L}$ ) developed malignant disorders more frequently compared to the ones with high $(100 \mathrm{KU} / \mathrm{L})$ and very high $(1000 \mathrm{KU} / \mathrm{L})$ IgE levels [9]. It was reported that the pre-diagnosis IgE levels were lower in cases diagnosed with CLL and multiple myeloma compared to the control group, and this was related to the clinical immunodeficiency observed before the diagnosis of cancer [27]. The relationship between IgE levels and cancer may indicate the role of T-Helper-2 mediated immune response in the development or control of some cancers. The studies conducted in line with this hypothesis have found that mice injected with breast cancer cells fight the tumor better and have a longer life span if they had a higher IgE level spontaneously [6]. Again, it was determined that tumor spread increased in mice whose lgE responses were destroyed, and tumor growth was well-controlled in mice with strong IgE responses [28]. There are more folate receptor alpha in many cancer cell types compared to the normal cells, and IgE type chimeric antibody (MOv18 IgE) phase 1 (ClinicalTrials.gov NCT02546921) trials have been carried out for this receptor [29]. Recently, numerous chimeric IgE studies have been carried out for use in cancer treatment [30].

In the light of all these data, the relationship between malignancy and IgE seems to be inversely proportional. The association of cancer (predominantly hematological cancers) with very low lgE levels appears to occur in absence of a known immunodeficiency. It is generally thought that atopy has a protective effect against cancer. In cases with very low IgE levels, there is a need for long-term prospective studies making repeated measurements and clinical follow-up of the patients order to determine whether malignancy is the result or cause, as well as studies that will reveal the unenlightened role of $\lg E$ in the 
immune system. We do not know whether IgE deficiency is a predisposing factor for cancer, or a sign of cancer prior to its development due to a modulation disorder in the immune system. In any case, in cases with IgE deficiency, this situation should be considered as a red flag, and the cases should be followed up closely in terms of cancer development even if the clinical picture is normal at that time.

The most common disorder in our patients was malignancies. Hematological malignancies were found in most of our patients, and solid tumors were less frequent. Among hematological malignancies; lymphoma, CLL and multiple myeloma were predominant. There were many solid tumor types.

In our study, autoimmune disorders were determined in $16.7 \%$ of the cases. As expected, this was found to be associated with autoantibody positivity, female gender and IgG elevation. Mainly, connective tissue disorders were evident. In the study of Smith et al. [3] the incidence of autoimmune disorders was found to be significantly higher in patients with low IgE levels compared to the control group. It is generally thought that there is an inversely proportional relationship between allergy and autoimmunity. It has been suggested that this relationship is T helper-induced, the Th2-mediated atopic disorders are less common in patients with Th1-mediated autoimmunity, and may prevent the development of autoimmunity or alleviate the clinical symptoms in allergic disorders where Th2 inflammation is more prominent $[31,32]$. In addition, it was claimed that gain-of-function mutation in the STAT3 is an immune deficiency accompanied by autoimmunity and recurrent infections. IgE level was found to be $<2 \mathrm{IU} / \mathrm{mL}$ in the ones with this mutation, and it was reported that it could be used as a screening test [33]. In another study, it was suggested that it could not be used as a screening test since its sensitivity and specificity were low [34]. In literature, the studies on IgE and autoimmunity are mostly on the development of IgE type of autoantibodies in autoimmune disorders $[12,35,36]$. It has been reported that the presence of IgE type autoantibodies is associated with disease activity in autoimmune disorders, particularly in SLE [11]. We do not know how and why IgE deficiency occurs in autoimmunity when the levels of other immunoglobulins are high. However, as is known, the incidence of autoimmune disorders increases in humoral immune deficiencies (selective $\lg A$ deficiency, etc.). $\lg \mathrm{E}$, like $\lg \mathrm{A}$, is an immunoglobulin with a more pronounced mucosal activity. Lack of neutralization of extrinsic antigens in the mucosa may lead to the establishment of autoimmune mechanisms. Although IgE deficiency is not yet included in the classification of primary immunodeficiencies, signs of an immune dysregulation are seen in our study and in the literature.

The cases in the immunodeficiency group mostly had humoral immunodeficiencies. It is an expected finding that all immunoglobulins will be affected in humoral ID. IgE deficiency is frequently seen in CVID, and correlates with low levels of other immunoglobulins [5]. Other causes of humoral immunodeficiency, ataxia telangiectasia and combined immunodeficiencies may also lead to IgE deficiency [4].

Since $\operatorname{lgE}$ is a mucosal immunoglobulin, it may play a role in the immune response in case of exposure to exogenous antigens. It has been shown that IgE production is insufficient in mice with experimental lymphotoxin deficiency, these mice have more airway inflammation and bronchial hyperactivity, but the 
inflammation is Th1 type [37]. In our study, atopic diseases were determined in 20 (11.1\%) patients, and airway disease was more common.

It has been determined that upper respiratory tract infections are more common in patients with very low IgE levels compared to patients with normal and high IgE levels [3,38]. In our study, mainly sinopulmonary infections were determined. No parasitic infections were found. In the literature, it has been reported that sino-pulmonary infections are frequently encountered in cases with very low IgE levels $[39,40]$. The role of IgE in mucosal defense may explain this condition.

In our study, the other diseases group constituted $37.5 \%$ of the child patients. The most common disorders in this group were neurological diseases, and resistant epilepsies were the most frequently encountered disorders. In these cases, IgE deficiency may often be associated with the use of antiepileptics. Anti-epileptics have been shown to reduce immunoglobulin levels $[41,42]$. Another reason was congenital heart anomalies requiring surgery. Most of our patients had aortic arch anomalies. The genetic disease most commonly associated with aortic arch anomalies is DiGeorge syndrome, which also causes low immunoglobulin levels [43]. In these patients, low lgE levels may be secondary to unspecified complete or incomplete Di-George syndrome or intervention to thymus during surgery. Severe protein energy malnutrition was detected in three patients. In adults, chronic renal failure, complicated diabetes, and aplastic anemia were the most common disorders. It has been known that medications used for chronic renal failure, malnutrition, and following renal transplantation cause hypogammaglobinemia [42].

The main limitations of the study are its retrospective design and the absence of a control group; and this led to failure in standardization. The IgE measurements of the cases were made predominantly before the diagnosis and during the diagnostic procedures. However, test results obtained after diagnosis were also available. IgG, IgA, IgM levels, and autoantibodies were not measured in every patient, and this caused data loss. Both IgE and other tests were ordered as the clinicians decided, not according to a standard algorithm.

Another limitation the study was lack of the control group, and hence not designing the study as a randomized controlled study, and lack of comparison with the groups with normal and high IgE levels. However, while planning the study, we wanted to learn how very low IgE levels are reflected in the clinical picture. Therefore, we wanted to analyze only cases with IgE deficiency.

The fact that the data were obtained from a limited sample group and the lack of any information on the prevalence of IgE deficiency in our country were other limitations of our study.

We hope that our study will guide further studies on the role of IgE in the pathogenesis of diseases and also the studies on targeted therapies.

\section{Conclusions}


IgE deficiency may accompany critical systemic disorders. Prospective studies are needed to establish a cause and effect relationship, and whether IgE deficiency plays a role in the pathophysiology of associated disorders. When encountered with very low IgE levels, it will be beneficial for clinicians to keep systemic disorders in mind, and to carry on investigations in line with the patient's complaints.

\section{Abbreviations}

Ig: Immunoglobulin

IU/mL: international units / milliliter

US: United States of America

CVID: Common variable immunodeficiency

EAACl: The European Academy of Allergy and Clinical Immunology

DEU: Dokuz Eylul University Faculty of Medicine

ANA: anti-nuclear antibody

Anti dsDNA: Anti-double stranded Deoxyribonucleic acids antibodies,

ENA: extractable nuclear antigens,

Anti TPO: Anti-thyroid peroxidase

Anti TG: Anti-thyroglobulin

ICD-10: The international disease classification 10

ID: Immune deficiency

CLL: Chronic Lymphoid Leukemia

SLE: Systemic lupus erythematosus

\section{Declarations}

\section{Author contrlbutlons}

All authors contributed to the study conception and design. Material preparation, data collection and analysis were performed by Serdar Al, Gizem Atakul, Özge Atay, Özge Kangallı, Işık Odaman Al, Suna Asilsoy, Nevin Uzuner and Özkan Karaman. The first draft of the manuscript was written by Serdar Al, 
Suna Asilsoy and all authors commented on previous versions of the manuscript. All authors read and approved the final manuscript.

\section{Funding}

None

\section{Confllct of Interest}

The authors declare that they have no conflict of interest

\section{Ethlcs approval}

This study was performed in line with the principles of the Declaration of Helsinki. Approval was granted by the Ethics Committee of Dokuz Eylul University Non-Interventional Studies Ethics Committee (Decision No: 2020/29-47).

\section{References}

1. Bennich HH, Ishizaka K, Johansson SG., Rowe DS, Stanworth DR, Terry WD. Immunoglobulin E, a new class of human immunoglobulin. Bull World Health Organ. 1968;38:151-2.

2. Elkuch $M$, Greiff V, Berger CT, Bouchenaki M, Daikeler T, Bircher A, et al. Low immunoglobulin $E$ flags two distinct types of immune dysregulation. Clin Exp Immunol. 2017;187:345-52.

3. Smith JK, Krishnaswamy GH, Dykes R, Reynolds S, Berk SL. Clinical Manifestations of IgE Hypogammaglobulinemia. Ann Allergy, Asthma Immunol. 1997;78.

4. Tangye SG, Al-Herz W, Bousfiha A, Chatila T, Cunningham-Rundles C, Etzioni A, et al. Human Inborn Errors of Immunity: 2019 Update on the Classification from the International Union of Immunological Societies Expert Committee. J Clin Immunol. Journal of Clinical Immunology; 2020;40:24-64.

5. Lawrence MG, Palacios-kibler T V, Workman LJ, Alexander J, Steinke JW, Payne SC, et al. Low Serum IgE is a Sensitive and Specific Marker for Common Variable Immunodeficiency (CVID). J Clin Immunol. 2019;38:225-33.

6. Singer J, Achatz-Straussberger G, Bentley-Lukschal A, Fazekas-Singer J, Achatz G, Karagiannis SN, et al. AllergoOncology: High innate lgE levels are decisive for the survival of cancer-bearing mice. World Allergy Organ J [Internet]. Elsevier Ltd; 2019;12:1-8. Available from: https://doi.org/10.1016/j.waojou.2019.100044

7. Cui Y, Hill AW. Atopy and Specific Cancer Sites: a Review of Epidemiological Studies. Clin Rev Allergy Immunol. 2016;51:338-352.

8. Ferastraoaru D, Bax HJ, Bergmann C, Capron M, Castells M, Dombrowicz D, et al. AllergoOncology: Ultra-low IgE, a potential novel biomarker in cancer - A Position Paper of the European Academy of Allergy and Clinical Immunology (EAACI). Clin Transl Allergy [Internet]. BioMed Central; 2020;10:116. Available from: https://doi.org/10.1186/s13601-020-00335-w 
9. Ferastraoaru D, Rosenstreich D. IgE deficiency is associated with high rates of new malignancies: Results of a longitudinal cohort study. J Allergy Clin Immunol Pract [Internet]. American Academy of Allergy, Asthma \& Immunology; 2020;8:413-5. Available from:

https://doi.org/10.1016/j.jaip.2019.06.031

10. Ettinger R, Karnell JL, Henault J, Panda SK, Riggs JM, Kolbeck R, et al. Pathogenic mechanisms of IgE-mediated inflammation in self-destructive autoimmune responses. Autoimmunity [Internet]. 2017;50:1:25-36. Available from: https://www.tandfonline.com/action/journallnformation? journalCode=iaut20

11. Sanjuan MA, Sagar D, Kolbeck R. Role of IgE in autoimmunity. J Allergy Clin Immunol. Mosby Inc.; 2016;137:1651-61.

12. Maurer M, Altrichter S, Schmetzer O, Scheffel J, Church MK, Metz M. immunoglobulin e-Mediated Autoimmunity. Front Immunol [Internet]. 2018;9:689. Available from: www.frontiersin.org

13. Roa S, Isidoro-Garcia M, Davila I, Laffond E, Lorente F, Rogelio G-S. Molecular analysis of activationinduced cytidine deaminase gene in immunoglobulin-E deficient patients. Clin Dev Immunol. 2008;2008.

14. Maltsev DV, Rybak IR, Gorbenko VY. Isolated deficiency of IgE in humans: update. Actual Infectology. 2017;5:1-7.

15. Ferastraoaru D, Rosenstreich D, Smith S. IgE deficient patients have no IgE-encoding B cells in the periphery - a pilot study. J Allergy Clin Immunol [Internet]. 2020;145. Available from: https://search.proquest.com/scholarly-journals/ige-deficient-patients-have-no-encoding-bcells/docview/2425695125/se-2?accountid=10527. doi: http://dx.doi.org/10.1016/j.jaci.2019.12.417.

16. Ferastraoaru D, Schwartz D, Rosenstreich D. Increased Malignancy Rate in Children With IgE Deficiency. J Pediatr Hematol Oncol. 2020;Publish Ah:1-6.

17. Fleisher TA. Laboratory Reference Values. In: Rich RR, Fleisher TA, Shearer WT, Schroeder HW, Frew AJ, Weyand CM, editors. Clin Immunol [Internet]. Fifth Edit. Elsevier Ltd; 2019. p. 1317-8. Available from: https://doi.org/10.1016/B978-0-7020-6896-6.00098-3

18. Salo PM, Arbes SJ, Jaramillo R, Calatroni A, Weir CH, Sever ML, et al. Prevalence of allergic sensitization in the United States: Results from the National Health and Nutrition Examination Survey (NHANES) 2005-2006. J Allergy Clin Immunol. 2014;134:350-9.

19. Sung H, Ferlay J, Siegel RL, Laversanne M, Soerjomataram I, Jemal A, et al. Global cancer statistics 2020: GLOBOCAN estimates of incidence and mortality worldwide for 36 cancers in 185 countries. CA Cancer J Clin. 2021;0:1-41.

20. Wulaningsih W, Holmberg L, Garmo H, Karagiannis SN, Ahlstedt S, Malmstrom H, et al. Investigating the association between allergen-specific immunoglobulin $\mathrm{E}$, cancer risk and survival. Oncoimmunology. 2016;5.

21. Helby J, Bojesen SE, Nielsen SF, Nordestgaard BG. IgE and risk of cancer in 37747 individuals from the general population. Ann Oncol [Internet]. Elsevier Masson SAS; 2015;26:1784-90. Available from: 
https://doi.org/10.1093/annonc/mdv231

22. Lehrer $\mathrm{S}$, Rheinstein $\mathrm{PH}$, Rosenzweig KE. Allergy may confer better survival on patients with gliomas. Clin Neurol Neurosurg [Internet]. 2019;177:63-7. Available from:

https://doi.org/10.1016/j.clineuro.2018.12.021

23. Linhares P, Carvalho B, Vaz R, Costa BM. Glioblastoma: Is there any blood biomarker with true clinical relevance? Int J Mol Sci. 2020;21:1-16.

24. Matta GME, Battaglio S, Dibello C, Napoli P, Baldi C, Ciccone G, et al. Polyclonal immunoglobulin E levels are correlated with hemoglobin values and overall survival in patients with multiple myeloma. Clin Cancer Res. 2007;13:5348-54.

25. Wrensch M, Wiencke JK, Wiemels J, Miike R, Patoka J, Moghadassi M, et al. Serum IgE, tumor epidermal growth factor receptor expression, and inherited polymorphisms associated with glioma survival. Cancer Res. 2006;66:4531-41.

26. Ferastraoaru D, Gross R, Rosenstreich D. Increased malignancy incidence in IgE deficient patients not due to concomitant Common Variable Immunodeficiency. Ann Allergy, Asthma Immunol. 2017;119:267-73.

27. Nieters A, Luczynska A, Becker S, Becker N, Vermeulen R, Overvad K, et al. Prediagnostic immunoglobulin E levels and risk of chronic lymphocytic leukemia, other lymphomas and multiple myeloma-results of the European Prospective Investigation into Cancer and Nutrition. Carcinogenesis. 2014;35:2716-22.

28. Nigro EA, Brini AT, Yenagi VA, Ferreira LM, Achatz-Straussberger G, Ambrosi A, et al. Cutting Edge: IgE Plays an Active Role in Tumor Immunosurveillance in Mice. J Immunol. 2016;197:2583-8.

29. Pellizzari G, Bax HJ, Josephs DH, Gotovina J, Jensen-Jarolim E, Spicer JF, et al. Harnessing Therapeutic IgE Antibodies to Re-educate Macrophages against Cancer. Trends Mol. Med. Elsevier Ltd; 2020. p. 615-26.

30. Chauhan J, McCraw AJ, Nakamura M, Osborn G, Sow HS, Cox VF, et al. IgE Antibodies against Cancer: Efficacy and Safety. Antibodies. 2020;9:55.

31. Bartůňková J, Kayserová J, Shoenfeld Y. Allergy and autoimmunity: Parallels and dissimilarity: The Yin and Yang of Immunopathology. Autoimmun Rev. 2009;8:302-8.

32. Rabin RL, Levinson Al. The nexus between atopic disease and autoimmunity: A review of the epidemiological and mechanistic literature. Clin Exp Immunol. 2008;153:19-30.

33. Johnson MB, Flanagan SEF, Martins TB, Hill HR, Hattersley AT, McDonald TJ. Low IgE Is a Useful Tool to Identify STAT3 Gain-of- Function Mutations. Clin Chem [Internet]. 2016;62:1536-8. Available from: https://academic.oup.com/clinchem/article/62/11/1536/5611997

34. Tangye SG, Forbes LR, Leiding J, Kahn P, Kumar AR, Gambineri E, et al. Low IgE Is Insufficiently Sensitive to Guide Genetic Testing of STAT3 Gain-of-Function Mutations. Clin Chem 639 [Internet]. 2017;63:1539-40. Available from: https://academic.oup.com/clinchem/article/63/9/1539/5612661

35. Kashiwakura J, Okayama Y, Furue M, Kabashima K, Shimada S, Ra C, et al. Most Highly Cytokinergic IgEs Have Polyreactivity to Autoantigens. Allergy Asthma Immunol Res [Internet]. 
2012;November;4:332-40. Available from: http://dx.doi.org/10.4168/aair.2012.4.6.332http://eaair.org

36. Kolkhir P, Pogorelov D, Olisova O, Maurer M. Comorbidity and pathogenic links of chronic spontaneous urticaria and systemic lupus erythematosus - a systematic review. Clin Exp Allergy. 2016;46:275-87.

37. Kang H-S, Blink SE, Chin RK, Lee Y, Kim O, Weinstock J, et al. Lymphotoxin Is Required for Maintaining Physiological Levels of Serum IgE That Minimizes Th1-mediated Airway Inflammation. J Exp Med [Internet]. Rockefeller University Press; 2003;198:1643-52. Available from: http://www.jem.org/cgi/doi/10.1084/jem.20021784

38. Magen E, Mishal J, Vardy D. Selective IgE deficiency and cardiovascular diseases. Allergy Asthma Proc. 2015;36:225-9.

39. Schoettler JJ, Schleissner LA, Heiner DC. Familial IgE deficiency associated with sinopulmonary disease. Chest. Elsevier; 1989;96:516-21.

40. Magen E, Schlesinger M, David M, Ben-Zion I, Vardy D. Selective lgE deficiency, immune dysregulation, and autoimmunity. Allergy Asthma Proc. 2014;

41. Godhwani N, Bahna SL. Antiepilepsy drugs and the immune system. Ann Allergy, Asthma Immunol [Internet]. American College of Allergy, Asthma \& Immunology; 2016;117:634-40. Available from: http://dx.doi.org/10.1016/j.anai.2016.09.443

42. Patel SY, Carbone J, Jolles S. The expanding field of secondary antibody deficiency: Causes, diagnosis, and management. Front Immunol. 2019;10.

43. Lackey A, Muzio M. DiGeorge syndrome. StatPearls [Internet] [Internet]. StatPearls Publishing; 2020 Jan-; 2020. p. 189-97. Available from: https://www.ncbi.nlm.nih.gov/books/NBK549798/?

\section{Tables}

Table 1. Demographic characteristics and immunoglobilin levels of patients with $\mathrm{lgE}<2.5 \mathrm{IU} / \mathrm{ml}$

\begin{tabular}{|lll|}
\hline & Children $(\mathrm{n}=80, \% 0,37)$ & Adults $(\mathrm{n}=100, \% 0,77)$ \\
\hline Median (range)year & $5(1-17)$ & $60(18-88)$ \\
\hline Female $(\mathrm{n}, \%)$ & $36(45)$ & $60(60)$ \\
Male/Female & $1,22: 1$ & $0,66: 1$ \\
\hline IgG (median-range) $(\mathrm{mg} / \mathrm{dL})$ & $520(82-2037)$ & $1013(302-2765)$ \\
\hline $\operatorname{lgA}($ median- range) $(\mathrm{mg} / \mathrm{dL})$ & $37(6-453)$ & $156(9-593)$ \\
\hline $\operatorname{lgM}$ (median- range) $(\mathrm{mg} / \mathrm{dL})$ & $56(20-245)$ & $81(15-687)$ \\
\hline $\operatorname{lgE}($ median- range) & $1,55(0,25-2,48)$ & $1,59(0-2,49)$ \\
\hline$(\mathrm{mg} / \mathrm{dL})$ & & \\
\hline
\end{tabular}


Table 2. The data of the patients with malignancy.

\begin{tabular}{|c|c|c|}
\hline & Children (n:11) & Adults(n:34) \\
\hline Male (\%) & $6(\% 55)$ & $15(\% 44)$ \\
\hline Male:Female & $1,2: 1$ & $0,79: 1$ \\
\hline Age (mean $\pm S D)$ & $9,1 \pm 4,7$ & $66 \pm 17$ \\
\hline Low $\operatorname{lgG} \mathrm{G}^{\square}(\%)$ & $5 / 10(\% 50)$ & $11 / 32(\% 34)$ \\
\hline Low $\lg A^{\square}(\%)$ & $2 / 9(\% 22)$ & 9/31(\%29) \\
\hline Low $\operatorname{lgM}^{\square}(\%)$ & $5 / 10(\% 50)$ & 7/27(\%26) \\
\hline $\lg \mathrm{E}(\mathrm{mg} / \mathrm{dL})$ & $1,48 \pm 0,55$ & $1,46 \pm 0,72$ \\
\hline \multicolumn{3}{|l|}{ Malignancy n (\%) } \\
\hline Hematological (n:30) & $6(\% 55)$ & $24(\% 71)$ \\
\hline Solid Tumor (n:15) & $5(\% 45)$ & $10(\% 29$ \\
\hline \multirow[t]{4}{*}{ Hematological } & Lymphoma $(5)^{2}$ & Lymphoma $(6)^{1}$ \\
\hline & $\operatorname{ALL}(1)$ & $\operatorname{KLL}(9)^{3}$ \\
\hline & - & Multiple Myeloma (8) \\
\hline & - & $\operatorname{MPN}(1)^{4}$ \\
\hline \multirow[t]{8}{*}{ Solid Tumor } & Neuroblastoma (2) & Colon Ca (2) \\
\hline & Ewing sarcoma (1) & Breast Ca (2) \\
\hline & Hepatoblastoma (1) & Lung Ca (1) \\
\hline & Ependymoma (1) & Pancreatic Ca (1) \\
\hline & & Renal Ca (1) \\
\hline & & Thyroid papillary $\mathrm{Ca}(1)$ \\
\hline & & Ureter Ca (1) \\
\hline & & Neuro-Endocrine Tumor (1) \\
\hline
\end{tabular}


${ }^{\square}$ Low immunoglobulin: Refers to $<(-) 2$ SDS. ${ }^{1}$ Bladder plasmacytoma developed in one patient during the follow-up period. ${ }^{2}$ Lymphoma developed in the patient with primary Ataxia telangiectasia. ${ }^{3}$ Sarcomatoid tumor developed in one patient.

${ }^{4}$ MPN: Chronic Myeloproliferative Neoplasms, CLL: Chronic lymphocytic leukemia, ALL: Acute lymphocytic leukemia Ca: Cancer

Table 3. The distribution of the adults with autoimmune disorders

\begin{tabular}{|lll|}
\hline Diseases & $\begin{array}{l}\text { Adult } \\
\mathbf{n : 2 6}(\%)\end{array}$ & Comorbid conditions \\
\hline Systemic Sclerosis & $5(\% 19)$ & Pulmonary involvement in 1 case \\
\hline Hashimato thyroiditis & $5(\% 19)$ & $\begin{array}{l}\text { Chronic urticaria in 3 cases, } 1 \text { pulmonary embolism, DM and } \\
\text { interstitial lung disease in 1 case }\end{array}$ \\
\hline SLE & $3(\% 12)$ & \\
\hline Sarcoidosis & $2(\% 8)$ & \\
\hline Psoriasis & $1(\% 4)$ & Spondyloartropathy \\
\hline $\begin{array}{l}\text { Inflammatory bowel } \\
\text { disease (IBD) }\end{array}$ & $1(\% 4)$ & Spondyloartropathy \\
\hline $\begin{array}{l}\text { Type 1 Diabetes } \\
\text { Mellitus (DM) }\end{array}$ & $2(\% 8)$ & Polyneuropathy in both cases \\
\hline $\begin{array}{l}\text { Interstitial lung } \\
\text { disease }\end{array}$ & $2(\% 8)$ & \\
\hline Sjogren's syndrome & $1(\% 4)$ & Interstitial lung disease \\
\hline Spondyloartropathy & $1(\% 4)$ & \\
\hline $\begin{array}{l}\text { Ankylosing } \\
\text { spondylitis }\end{array}$ & $1(\% 4)$ & Chronic renal failure+kidney transplantation \\
\hline $\begin{array}{l}\text { Multiple sclerosis } \\
\text { Retroperitoneal }\end{array}$ & $1(\% 4)$ & \\
\hline fibrosis & $1(\% 4)$ & \\
\hline
\end{tabular}

\section{Figures}


Disease groups in children with $\mathrm{IgE}<2.5 \mathrm{IU} / \mathrm{ml}$

(age $<18$ years) n: 80

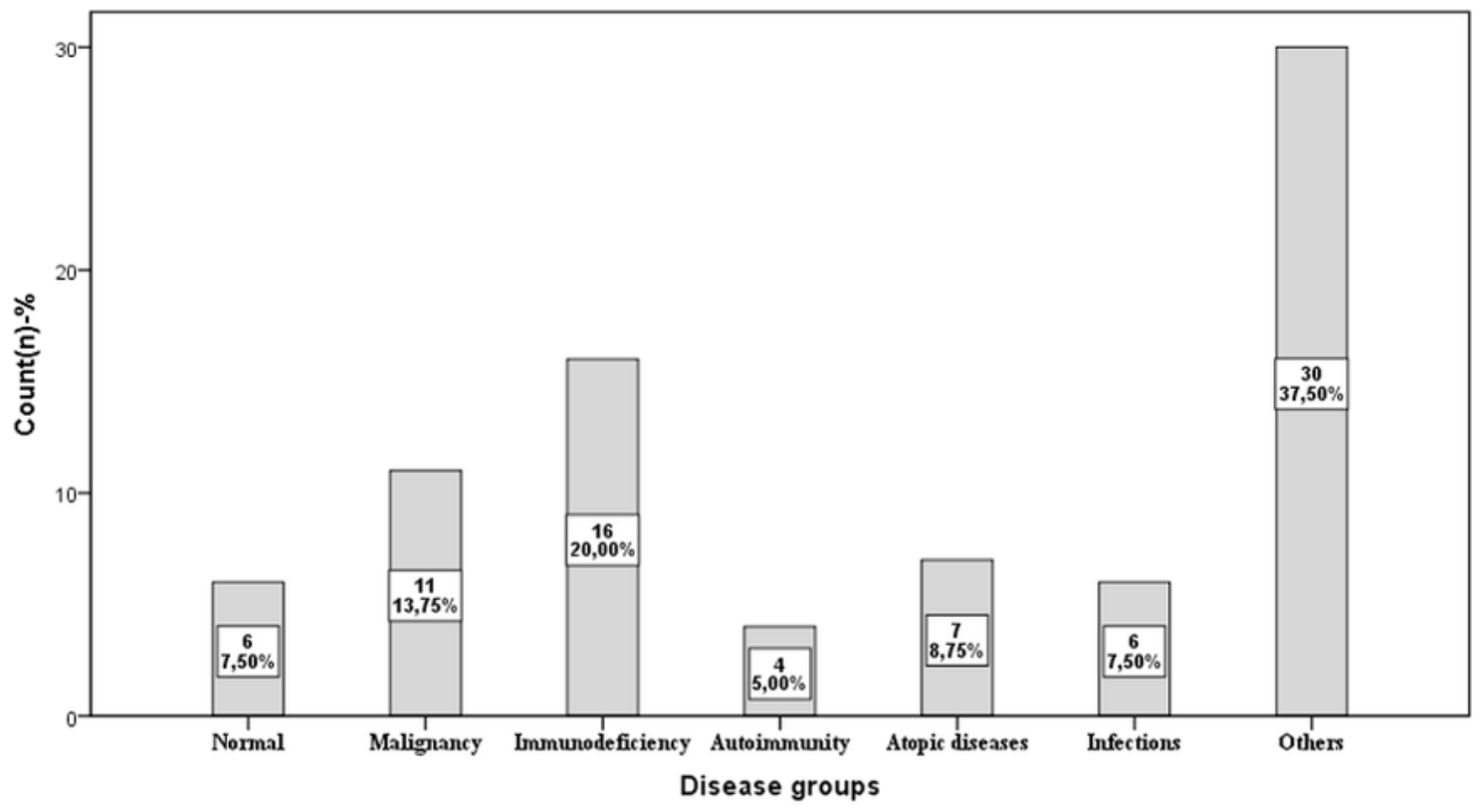

Disease groups in adult with $\mathrm{lg} \mathrm{E}<2.5 \mathrm{IU} / \mathrm{ml}$

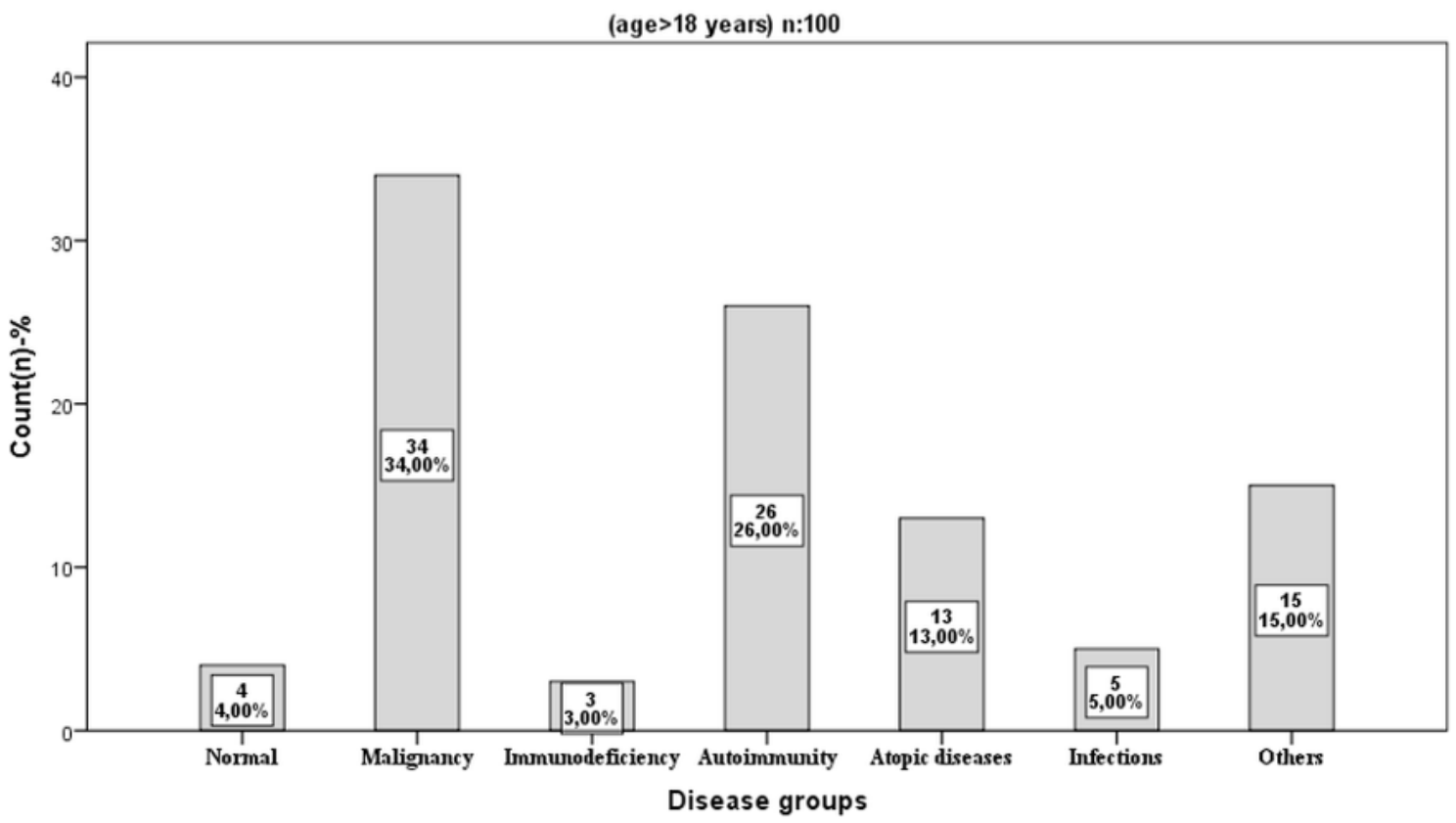

Figure 1

The distribution of the children and the adults with an $\mathrm{IgE}$ level $<2.5 \mathrm{IU} / \mathrm{mL}$ by the disease groups. 


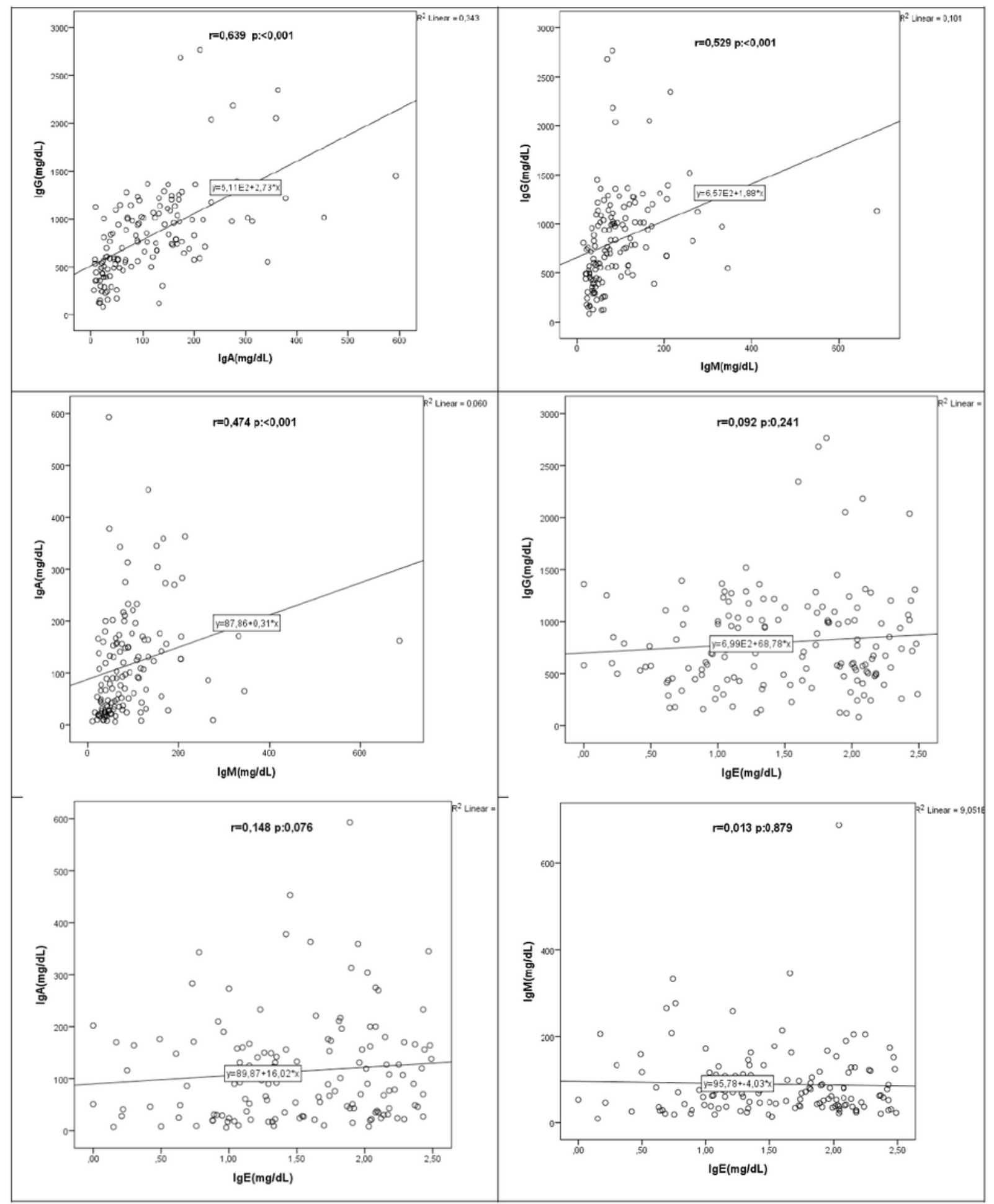

Figure 2

The graph showing the correlations of immunoglobulins 


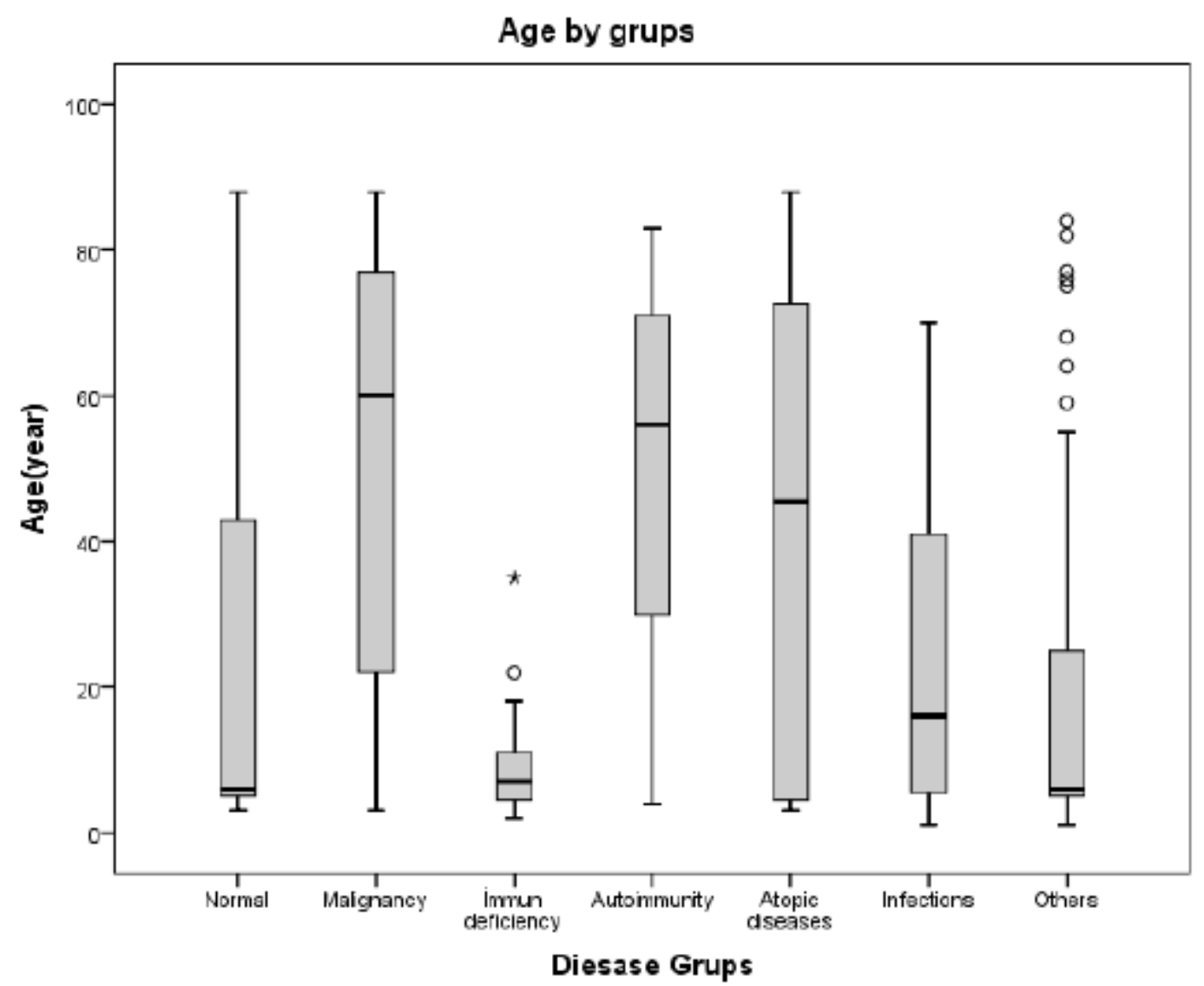

Figure 3

Age distribution of the disease groups 